\title{
Manipulação da Altura de Corte da Planta de Milho (Zea mays, L.) para Ensilagem Visando a Produção do Novilho Superprecoce
}

\section{João Restle ${ }^{1}$, Mikael Neumann ${ }^{2}$, Ivan Luiz Brondani ${ }^{3}$, Leonir Luiz Pascoal ${ }^{3}$, José Henrique Souza da Silva ${ }^{4}$, Luiz Giovani de Pellegrini ${ }^{5}$, Alexandre Nunes Motta de Souza ${ }^{6}$}

RESUMO - O experimento foi conduzido com o objetivo de avaliar o desempenho de bezerros de corte terminados em confinamento, alimentados com silagem do híbrido de milho AG-5011 colhida a alturas de corte diferenciadas: cortes baixo $(20 \mathrm{~cm})$ e alto $(42 \mathrm{~cm})$. Foram utilizados 12 bezerros Braford com idade média de sete meses e peso médio inicial de $209 \mathrm{~kg}$. O confinamento compreendeu um período total de 126 dias, sendo subdividido em dois períodos de avaliação de 63 dias, em que a relação volumoso:concentrado foi de 60:40 e 50:50para o primeiro período e segundo períodos de confinamento, respectivamente. A silagem obtida com corte alto apresentou maior DIVMO (66,67 contra 58,60\%) e menor concentração de FDN (41,47 contra 47,80\%). Houve interação entre altura de corte e período de avaliação para os consumos diários de matéria seca (CMS) e de energia digestível (CED) expresso em porcentagem do peso vivo e por unidade tamanho metabólico, ganho de peso médio diário (GMD), conversão alimentar (CA) e eficiência energética (CE). Animais que tiveram incluída à dieta alimentar silagem de corte alto, na primeira fase de confinamento, apresentaram maior GMD (1,352 contra 1,198 kg) e melhor CA (4,82 contra 5,39 kg de MS/kg de ganho de peso) frente à silagem de corte baixo. No entanto, com a redução da relação volumoso:concentrado na segunda fase para 50:50, o GMD (1,228 contra 1,336 kg) e CA (6,43 contra 6,34 kg de MS/kg de ganho de peso) foram similares. Os pesos de abate, de carcaça fria, o rendimento de carcaça fria e a espessura de gordura das carcaças foram similares, sendo, respectivamente, 371,8 $\mathrm{kg} ; 195,3 \mathrm{~kg} ; 52,46 \%$; e $5,7 \mathrm{~mm}$ para o corte alto e $368,2 \mathrm{~kg} ; 195,7 \mathrm{~kg} ; 53,08 \%$; e 3,7 mm para o corte baixo.

Palavras-chave: bovinos de corte, Braford, consumo alimentar, conversão alimentar, ganho de peso

\section{Corn (Zea mays, L.) Cutting Height during Silage Processing for Young Beef Cattle Production}

ABSTRACT - The experiment was conducted with the objective to evaluate the performance of feedlot finished calves, fed with silages of AG-5011 corn hybrid harvested with different cutting height: low cut $(20 \mathrm{~cm})$ and high cut $(42 \mathrm{~cm})$. Twelve Braford calves with an average age of seven months and average live weight of $209 \mathrm{~kg}$, were used. The feedlot period was 126 days, divided in two periods of the 63 days The roughage:concentrate ratio was 60:40 and 50:50 for the first and second periods, respectively. The high cut silage showed higher IVOMD ( 66.67 vs $58.60 \%)$ and lower NDF (41.47 vs $47.80 \%)$. Significant interaction was observed between cutting height and evaluation period for dry matter intake (DMI) expressed per $100 \mathrm{~kg}$ of live weight and per unit of metabolic weight, digestible energy intake (DEI), weight gain (ADG), feed conversion (FC) and energy efficiency (EE). Animals fed with the high cut silage during the first period presented higher $\operatorname{ADG}(1.352 \mathrm{vs} 1.198 \mathrm{~kg})$ and better FC ( $4.82 \mathrm{vs} 5.39 \mathrm{~kg}$ of DM $/ \mathrm{kg} \mathrm{LW})$ than animals fed with the low cut silage. However, with the reduction of the roughage:concentrate ratio to 50:50 during the second period, the ADG (1.228 vs $1.336 \mathrm{~kg}$ ) and FC (6.43 vs 6.34 kg of DM/kg LW) were similar. Slaughter and cold carcass weight, dressing percentage and subcutaneous fat thickness were similar, being, respectively, $371.8 \mathrm{~kg} ; 195.3 \mathrm{~kg} ; 52.46 \%$; and $5.7 \mathrm{~mm}$ for the higher cut and $368.2 \mathrm{~kg} ; 195.7 \mathrm{~kg} ; 53.08 \%$; and $3.7 \mathrm{~mm}$ for the lower cut.

Key Words: beef cattle, Braford, dry matter intake, feed conversion, weight gain

\section{Introdução}

O uso de forragem conservada de alta qualidade, combinada ao uso de grãos e de resíduos e/ou subprodutos agroindustriais, é uma alternativa viável na produção de bovinos confinados (Brondani et al., 2000). Segundo Alves Filho et al. (2000), o milho é uma cultura consagrada para confecção de silagem no Brasil, por apresentar elevada produção de massa verde por unidade de área e excelente qualidade de fermentação e manutenção do valor nutritivo da massa ensilada. Além disso, apresenta boa aceitabilidade por parte dos bovinos.

Segundo Nussio (1992), trabalhos de pesquisa

\footnotetext{
${ }^{1}$ Eng ${ }^{\circ}-A g r{ }^{\circ}$, PhD., Pesquisador do CNPq, Professor Titular do Departamento de Zootecnia da UFSM - Campus Camobi, 97119-900, Santa

Maria - RS. E.mail: jorestle@ccr.ufsm.br

2 Eng ${ }^{\circ}-A g r^{\circ}$, MSc., Departamento de Zootecnia da UFSM. E.mail: mikaelneumann@hotmail.com

3 Zootecnista, MSc., Professor do Departamento de Zootecnia da UFSM.

${ }^{4}$ Eng $^{\circ}-$ Agro $^{\circ}$, PhD., Professor Adjunto do Departamento de Zootecnia da UFSM.

${ }^{5}$ Aluno de Graduação do curso de Medicina Veterinária da UFSM, Bolsista PIBIC-CNPq.

${ }^{6}$ Aluno de Graduação do curso de Medicina Veterinária da UFSM, Bolsista IC-CNPq.
} 
têm demonstrado que a produção de silagem de alta qualidade depende da composição física das estruturas anatômicas da planta de milho, devendo apresentar em torno de 60 a $65 \%$ de espigas, o que define a participação em torno de $45 \%$ de grãos no material ensilado. $\mathrm{O}$ autor também pondera sobre a importância do valor nutritivo de colmo e folhas da planta em processos de seleção de híbridos para a produção de silagem.

Entre outras técnicas, a possibilidade de manipulação do processo de colheita do milho para ensilagem, com a elevação da altura de corte das plantas, permite maior participação de grãos na massa ensilada, em detrimento da participação de colmos e folhas senescentes, resultando, segundo Restle et al. (1999), em melhoria da qualidade da silagem produzida, devido aos decréscimos significativos nos teores de fibra em detergente neutro e detergente ácido da silagem.

O objetivo do presente trabalho de pesquisa foi avaliar o efeito da manipulação da altura de corte das plantas de milho para produção de silagem sobre os parâmetros relativos à resposta animal de bezerros de corte terminados em confinamento.

\section{Material e Métodos}

O experimento foi conduzido no Setor de Bovinocultura de Corte do Departamento de Zootecnia da Universidade Federal de Santa Maria, localizada fisiograficamente na Depressão Central do Estado do Rio Grande do Sul, a uma altitude de $95 \mathrm{~m}$. Cartograficamente, localiza-se a $29^{\circ} 43^{\prime}$ de latitude

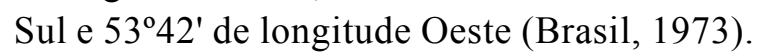

O clima da região é o Cfa (subtropical úmido), conforme classificação de Köppen, com precipitação média anual de $1.769 \mathrm{~mm}$, temperatura média anual de $19,2^{\circ} \mathrm{C}$, com média mínima de $9,3^{\circ} \mathrm{C}$ em julho e média máxima de $24,7^{\circ} \mathrm{C}$ em janeiro, insolação de 2.212 horas anuais e umidade relativa do ar de $82 \%$ (Moreno, 1961).

Os tratamentos testados corresponderam à dietas alimentares de bezerros de corte, que incluíram a silagem do híbrido de milho AG-5011 colhida a duas alturas de corte das plantas: T1 - corte baixo $(20 \mathrm{~cm})$ e $\mathrm{T} 2$ - corte alto $(42 \mathrm{~cm})$.

As plantas de milho foram colhidas quando a massa apresentou ao redor de $30 \%$ de matéria seca, com auxílio de uma ensiladeira regulada para o tamanho médio de picado de 1 a $1,5 \mathrm{~cm}$. O material colhido foi armazenado e compactado com auxílio de um trator, em silos de superfície tipo "torta", vedados e protegidos com lona plástica de polietileno de três camadas.

A alimentação e a avaliação do desempenho e o consumo de alimentos dos animais compreendeu um período de 126 dias de confinamento, sendo subdividido em dois períodos de avaliação de 63 dias.

A relação volumoso:concentrado para ambas as dietas experimentais (T1 - corte baixo e T2 - corte alto), com base na matéria seca, foi de 60:40 e 50:50 para o primeiro e segundo períodos de avaliação do confinamento, respectivamente. As dietas alimentares oferecidas aos bezerros foram isoprotéicas com 13,3\% de proteína bruta para o primeiro e segundo períodos de avaliação. A composição das dietas experimentais encontra-se na Tabela 1.

O sistema de alimentação foi ad libitum duas vezes ao dia, a primeira pela manhã às $8 \mathrm{~h}$ e a segunda às $16 \mathrm{~h}$ de cada dia. $\mathrm{O}$ ajuste do fornecimento da quantidade de alimento in natura foi calculado diariamente, considerando uma sobra de $10 \%$ da matéria seca oferecida em relação a consumida, sendo primeiramente distribuído o volumoso no comedouro e sobre o mesmo o concentrado, realizando-se em seguida a mistura. O consumo voluntário dos alimentos foi registrado diariamente por meio da pesagem da quantidade oferecida e das sobras do dia anterior.

Foram utilizados 12 bezerros, da raça Braford (5/8 Hereford 3/8 Nelore), com idade média de sete meses e peso vivo médio inicial de $209 \mathrm{~kg}$, distribuídos em quatro boxes de confinamento com três animais cada. Os animais foram submetidos a um período de 18 dias de adaptação às instalações e ao sistema de manejo das dietas experimentais. Neste período, realizou-se a aplicação de um vermífugo de amplo espectro.

Os animais foram pesados, após jejum de sólidos de 12 horas, no início e no final do período experimental, com pesagens intermediárias a cada 21 dias.

Foram coletadas amostras representativas dos componentes da dieta alimentar no início da adaptação e a cada período de avaliação do experimento. Estas amostras foram pré-secas em estufa de ar forçado a $60^{\circ} \mathrm{C}$ por 72 horas, para determinação do teor de matéria seca, sendo seqüencialmente processadas em moinho tipo "Willey" com peneira de malha de um milímetro. Posteriormente, nas amostras de cada alimento foram determinados o teor de matéria seca total (MS) e o teor de matéria mineral (MM), por incineração a $550^{\circ} \mathrm{C}$, obtendo-se por diferença o teor de matéria orgânica $(\mathrm{MO}=100-\mathrm{MM})$ e nitrogênio

R. Bras. Zootec., v.31, n.3, p.1235-1244, 2002 
Tabela 1 - Composição percentual dos ingredientes nas dietas experimentais, com base na matéria seca total Table 1 - Composition (\%) of the experimental diets, total dry matter basis

\begin{tabular}{|c|c|c|c|c|}
\hline \multirow[t]{3}{*}{$\begin{array}{l}\text { Constituintes } \\
\text { Components }\end{array}$} & \multicolumn{4}{|c|}{$\begin{array}{l}\text { Períodos de avaliação } \\
\text { Evaluation period }\end{array}$} \\
\hline & \multicolumn{2}{|c|}{$\begin{array}{c}12 / 06 \text { a } 13 / 08 / 1997 \\
06 / 12 \text { to } 08 / 13\end{array}$} & \multicolumn{2}{|c|}{$\begin{array}{c}14 / 08 \text { a } 16 / 10 / 1997 \\
08 / 14 \text { to } 10 / 16 \\
\end{array}$} \\
\hline & $\begin{array}{l}\text { Corte baixo }(20 \mathrm{~cm}) \\
\text { Low cut }(20 \mathrm{~cm})\end{array}$ & $\begin{array}{l}\text { Corte alto }(42 \mathrm{~cm}) \\
\text { High cut }(42 \mathrm{~cm})\end{array}$ & $\begin{array}{l}\text { Corte baixo }(20 \mathrm{~cm}) \\
\text { Low cut }(20 \mathrm{~cm})\end{array}$ & $\begin{array}{l}\text { Corte alto }(42 \mathrm{~cm}) \\
\text { High cut }(42 \mathrm{~cm})\end{array}$ \\
\hline $\begin{array}{l}\text { Volumoso (Silagem de milho) } \\
\text { Roughage (Corn silage) } \\
\text { Concentrado } \\
\text { Concentrate }\end{array}$ & 60,00 & 60,00 & 50,00 & 50,00 \\
\hline $\begin{array}{l}\text { - Farelo de soja } \\
\text { - Soybean meal }\end{array}$ & 12,16 & 12,16 & 11,26 & 11,26 \\
\hline $\begin{array}{l}\text { - Sorgo grão } \\
\text { - Sorghum grain }\end{array}$ & 22,74 & 22,74 & 32,24 & 32,24 \\
\hline $\begin{array}{l}\text { - Farelo de arroz desengordurado } \\
\text { - Rice bran }\end{array}$ & 4,00 & 4,00 & 5,00 & 5,00 \\
\hline $\begin{array}{l}\text { - Sal comum } \\
\text { - Salt }\end{array}$ & 0,70 & 0,70 & 1,25 & 1,25 \\
\hline $\begin{array}{l}\text { - Calcário calcítico } \\
\text { - Limestone }\end{array}$ & 0,40 & 0,40 & 0,25 & 0,25 \\
\hline $\begin{array}{l}\text { Total } \\
\text { Total }\end{array}$ & 100,00 & 100,00 & 100,00 & 100,00 \\
\hline
\end{tabular}

total pelo método micro kjeldahl, o qual foi multiplicado pelo fator 6,25 para obtenção do teor de proteína bruta(PB), conforme AOAC (1984), e a digestibilidade in vitro da matéria orgânica (DIVMO) (Tilley \& Terry, 1963). Para os componentes físicos da planta, determinou-se a fibra em detergente neutro (FDN), conforme Goering \& Van Soest (1970). Para o cálculo de energia digestível (ED), utilizaram-se as equações descritas pelo ARC (1980), com base na digestibilidade in vitro da matéria orgânica (DIVMO) e no teor de matéria orgânica (MO), sendo calculado, a partir desta, a energia metabolizável(EM), multiplicando-se a ED pelo fator 0,82.

Os parâmetros estimados foram consumo médio diário de matéria seca, expresso em $\mathrm{kg}$ /animal (CMSD), por $100 \mathrm{~kg}$ de peso vivo (CMSP) e por unidade de tamanho metabólico (CMSM), bem como o consumo médio diário de energia digestível, expresso em Mcal/animal (CEDD), por $100 \mathrm{~kg}$ de peso vivo (CEDP) e por unidade tamanho metabólico (CEDM), ganho de peso médio diário (GMD), conversão alimentar (CA) e eficiência energética (CE).

O comportamento produtivo da lavoura e a composição física percentual da estrutura da planta e da silagem de milho submetida aos dois sistemas de altura de corte $(20$ e $42 \mathrm{~cm}$ ) foram comparados por intermédio de análise descritiva amostral dos dados coletados.
O delineamento experimental foi o inteiramente casualizado, composto por dois tratamentos (dietas com silagem de milho colhida às alturas de corte de 20 ou $42 \mathrm{~cm}$ ), com duas repetições. Cada unidade experimental foi composta por um lote de três animais.

Os dados coletados de cada parâmetro foram submetidos à análise de variância, por meio do pacote estatístico SAS (1993), e as diferenças entre as médias foram analisadas pelo teste de $\mathrm{F}$, a $5 \%$ de significância.

O modelo estatístico utilizado foi o seguinte: Yijkl $=\mathrm{m}+\mathrm{ACi}+\mathrm{Rj}(\mathrm{AC}) \mathrm{i}+\mathrm{Pk}+(\mathrm{AC} * \mathrm{P}) \mathrm{ik}+\mathrm{Eijkl}$, em que: $Y i j k l=$ variáveis dependentes; $\mathrm{m}=$ média das observações; $\mathrm{ACi}=$ efeito da altura de corte de ordem "i", sendo 1 (silagem de milho colhida à altura de corte de $20 \mathrm{~cm}$ ) e 2 (silagem de milho colhida à altura de corte de $42 \mathrm{~cm}$ ); $\mathrm{Rj}(\mathrm{AC}) \mathrm{i}=$ efeito aleatório baseado na repetição dentro do tratamento (ACi) (Erro a); Pk = efeito do período de avaliação de ordem " $\mathrm{j}$ ", sendo 1 (primeiro período, com relação volumoso:concentrado de 60:40) e 2 (segundo período, com relação volumoso:concentrado de 50:50); $(\mathrm{AC} * \mathrm{P}) \mathrm{ik}=$ efeito da interação entre o tratamento altura de corte de ordem "i" e período de avaliação de ordem "k"; e Eijkl = erro aleatório residual, assumindo distribuição normal média igual a zero e variância $\sigma^{2}$ (Erro b). 


\section{Resultados e Discussão}

Na Tabela 2 é apresentado o resultado da análise bromatológica dos alimentos utilizados nas dietas experimentais. O híbrido AG-5011, quando colhido a $42 \mathrm{~cm}$ de altura, produziu uma silagem com menor teor de MS, maior DIVMO, maior teor de PB e maior concentração de ED em relação à silagem produzida a partir do corte das plantas a $20 \mathrm{~cm}$ de altura.

A elevação da altura de colheita das plantas de milho de 20 para $42 \mathrm{~cm}$ conferiu maior valor nutritivo a silagem, pois proporcionou aumento percentual na ordem de $13,77 \%$ no coeficiente de DIVMO e de $13,40 \%$ na concentração energética da massa ensilada, além de redução de 13,24\% no teor de FDN.

$\mathrm{Na}$ Tabela 3 são apresentadas as características agronômicas do híbrido AG-5011, de acordo com a manipulação da altura de colheita das plantas para ensilagem.

$\mathrm{Na}$ composição física percentual das estruturas anatômicas da massa ensilada, verifica-se que a elevação da altura de corte das plantas de milho de $20 \mathrm{~cm}$ para $42 \mathrm{~cm}$ promoveu maior participação do componente folhas e espigas e menor participação de colmo na massa ensilada. A maior concentração de ED por $\mathrm{kg}$ de MS ensilada e a redução dos valores de FDN da silagem (Tabela 2) ocorreram em função da maior participação de folhas e espigas, em detrimento da participação do componente colmo na massa ensilada, comparativamente ao sistema de colheita a $20 \mathrm{~cm}$ de altura. A elevação da altura de corte do milho de 20 para $42 \mathrm{~cm}$ também demonstrou, por intermédio da análise da qualidade da fração fibrosa dos componentes toco remanescente e colmo ensilado, que a porção basal do colmo concentra maiores teores de FDN $(67,08$ contra $65,57 \%)$ frente à porção mediana + apical ensilada, sendo de $62,17 \%$ no corte de $20 \mathrm{~cm}$ de altura e $60,84 \%$ no corte de $42 \mathrm{~cm}$.

Na Tabela 4 constam os dados sobre o consumo de matéria seca. A interação entre altura de corte da

Tabela 2 - Teores médios percentuais de matéria seca (MS), digestibilidade in vitro da matéria orgânica (DIVMO), matéria orgânica (MO), proteína bruta (PB), fibra em detergente neutro (FDN), energia digestível (ED) e energia metabolizável (EM) dos componentes das dietas experimentais, com base na matéria seca total

Table 2 - Average percentages of dry matter (DM), in vitro organic matter digestibility (IVOMD), organic matter (OM), crude protein $(C P)$, neutral detergent fiber (NDF), digestible energy (DE) and metabolizable energy (ME) of the diets components, total dry matter basis

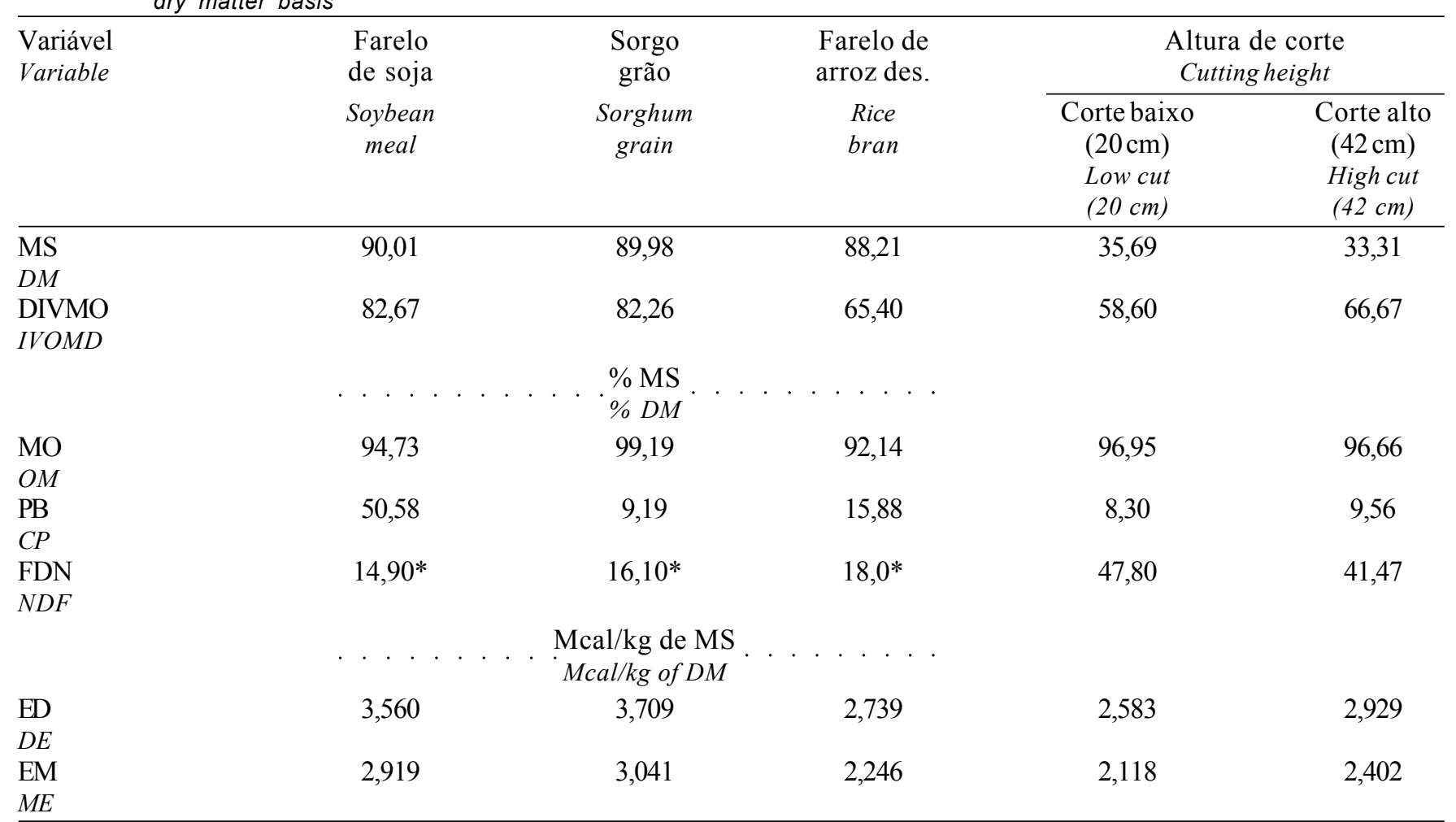

* Dados compilados do NRC (1984).

* Data taken from NRC (1984).

R. Bras. Zootec., v.31, n.3, p.1235-1244, 2002 
Tabela 3 - Altura de planta e altura de inserção da espiga, produção de matéria verde, produção de matéria seca, composição física percentual da planta e teores de FDN dos componentes da planta

Table 3 - Plant and ear height, green matter production, dry matter production, percentage of plant physical composition and NDF contents of plant components

\begin{tabular}{lcc}
\hline Variável & \multicolumn{2}{c}{ Altura de corte } \\
Variable & \multicolumn{2}{c}{ Cutting height } \\
\cline { 2 - 3 } & Corte baixo $(20 \mathrm{~cm})$ & Corte alto $(42 \mathrm{~cm})$ \\
& Low cut $(20 \mathrm{~cm})$ & High cut $(42 \mathrm{~cm})$ \\
\hline
\end{tabular}

Altura:

Height

- Planta, cm

221

221

Plant

- Espiga, cm

111

111

Ear

Produção:

Production

- Matéria verde, kg/ha 33.564

Green matter

- Matéria seca, kg/ha 10.945

Dry matter

Composição

na base seca

Dry matter basis

composition

- Toco

Stub

- Colmo

Stem

- Folhas

Leaves

- Espiga

Ear

Teores de FDN:

NDF contents

- Toco

Stub

- Colmo

Stem

- Folhas

Leaves

- Palha da espiga

Ear straw

- Sabugo

Corncob

planta do milho e período de avaliação não foi significativa $(\mathrm{P}>0,05)$ para o CMS expresso em $\mathrm{kg} / \mathrm{dia}$ (CMSD). No entanto, quando expresso como porcentagem do peso vivo (CMSP) e por unidade de tamanho metabólico (CMSM), a interação entre altura de corte e período de avaliação foi significativa.

O CMSD foi similar entre as dietas que tiveram a inclusão de silagem de milho colhida a $20 \mathrm{~cm}$ $(7,43 \mathrm{~kg})$ e $42 \mathrm{~cm}(7,20 \mathrm{~kg})$. Na análise dos períodos de avaliação do confinamento para o CMSD, maiores consumos $(\mathrm{P}<0,05)$ foram observados no segundo período de avaliação (8,16 contra $6,47 \mathrm{~kg} / \mathrm{dia})$.

$\mathrm{A}$ adição de $10 \%$ de grão de sorgo à fração concentrada da dieta dos animais (Tabela 1) promoveu o aumento dos teores de MS e do coeficiente de digestibilidade das dietas experimentais, que, associado ao desenvolvimento corporal dos animais com o avanço do período do confinamento, conferiu aumento percentual médio de 26,12\% no CMSD. Segundo McDonald et al. (1991), a ingestão de MS voluntária relaciona-se diretamente com o conteúdo de MS da dieta, a qual determina o espaço ocupado no trato gastrointestinal. Pimentel et al. (1998), avaliando diferentes híbridos de milho e sorgo, verificaram a tendência de maiores consumos de MS em animais cujas dietas apresentaram silagens com maiores teores de MS.

Conduzindo trabalho sobre alturas de corte, Restle et al. (1999) demonstraram que a utilização de dietas alimentares constituídas de silagem do híbrido de milho AG-5011 colhido às alturas de 16 e $46 \mathrm{~cm}$, associadas aos níveis de 16 e $30 \%$ de concentrado na alimentação de bezerros Braford confinados, não promoveu diferenças significativas nos CMSD dos animais que tiveram incluída na dieta silagem de corte baixo $(6,82 \mathrm{~kg} / \mathrm{dia})$ em relação à silagem de corte alto $(6,79 \mathrm{~kg} / \mathrm{dia})$.

Mertens (1994) sugere que, para alimentos que limitam o consumo por distenção ruminal, o consumo é melhor expresso em porcentagem do peso vivo, já que o efeito de enchimento da dieta tem estreita relação com o tamanho e a capacidade do trato gastrointestinal. Ainda segundo o mesmo autor, para aquelas dietas em que o consumo é limitado fisiologicamente, a melhor forma de expressar o consumo voluntário é em relação ao peso corporal metabólico. Como pode ser observado na Tabela 4, o CMSP foi semelhante $(\mathrm{P}>0,05)$ entre o primeiro $(2,61 \% \mathrm{PV}) \mathrm{e}$ segundo períodos de confinamento $(2,58 \% \mathrm{PV})$ para os bezerros cuja dieta incluía silagem colhida a $20 \mathrm{~cm}$. Já para os bezerros que tiveram a inclusão da silagem colhida a $42 \mathrm{~cm}$ na dieta alimentar, o CMSP decresceu significativamente $(\mathrm{P}<0,05)$ do primeiro $(2,58 \%$ PV) para o segundo período $(2,37 \%$ PV) de confinamento. A maior participação da fração concentrada na dieta alimentar no segundo período de confinamento contribuiu favoravelmente para manter o mesmo CMSP nos animais que receberam silagem

R. Bras. Zootec., v.31, n.3, p.1235-1244, 2002 
de plantas submetidas a corte baixo, enquanto o CMSP dos animais que receberam a silagem proveniente de plantas submetidas a corte alto foi reduzido em $8,1 \%$, com a transição do primeiro para o segundo período, demonstrando haver um efeito interativo entre a qualidade do volumoso definida pela altura de colheita das plantas e o aumento da fração concentrada das dietas experimentais. Várias são as teorias que visam explicar os mecanismos que controlam o consumo alimentar em bovinos (Mertens, 1994; Allen, 1996; Forbes, 1996). É provável que a redução no CMSP no segundo período do tratamento com silagem proveniente de plantas submetidas a corte alto tenha sido causada pelo aumento na concentração energética da dieta e sua relação com fatores metabólicos ou fisiológicos (Forbes, 1996). Segundo Illius \& Jessop (1996), as concentrações e os fluxos de nutrientes e energia, incluindo a produção e a velocidade com que são produzidos os ácidos graxos voláteis durante a fermentação no rúmen, são fatores que estão envolvidos no controle do consumo voluntário.

Verifica-se, na Tabela 4, que o CMSM aumentou $(\mathrm{P}<0,05)$ do primeiro para o segundo período no tratamento que incluiu a silagem proveniente de plantas submetidas a corte baixo $\left(103,51\right.$ contra $\left.109,82 \mathrm{~g} / \mathrm{kg}^{0,75}\right)$. Já na silagem proveniente de plantas submetidas a corte alto, o CMSM manteve-se constante do primeiro para o segundo período.

Em trabalho conduzido por Restle et al. (1999), não foi verificado efeito significativo do fator altura de corte da planta de milho (16 contra $46 \mathrm{~cm}$ ) sobre o CMS, seja expresso por porcentagem de peso vivo (2,20 contra $2,26 \% \mathrm{PV})$ ou por unidade de tamanho metabólico (122 contra $123 \mathrm{~g} / \mathrm{kg}^{0,75}$ ). Resultados inferiores aos do presente experimento para CMS foram observados por Brondani et al. (2001), que avaliaram o desempenho de bezerros Hereford e Aberdeen Angus em confinamento, visando à produção do superprecoce, utilizando dietas alimentares com níveis de 12 e $32 \%$ de concentrado associados a silagem de milho do AG-5011, sendo o CMSP de 2,09 e $2,06 \%$ e o CMSM de 86,36 e $85,15 \mathrm{~g} / \mathrm{kg}^{0,75}$, respectivamente, para os dois níveis de concentrado. Em seus estudos, Rosa et al. (2001) avaliaram o efeito de dietas alimentares com silagens de diferentes híbridos de milho sobre o desempenho de bezerros cruza Charolês e Nelore em confinamento, verificando para o híbrido AG-5011 CMSP de 2,13\% e CMSM de $89,05 \mathrm{~g} / \mathrm{kg}^{0,75}$, que também foram inferiores aos verificados no presente experimento.
$\mathrm{Na}$ Tabela 5 é apresentado o consumo de energia digestível, nas diferentes formas de expressão. Não houve interação significativa $(\mathrm{P}>0,05)$ entre altura de corte do milho e período de avaliação para o CED expresso em Mcal/dia (CEDD). Não houve diferença $(\mathrm{P}>0,05)$ entre as duas silagens para o CEDD. Embora a concentração energética tenha sido maior na silagem colhida a $42 \mathrm{~cm}$ que na colhida a $20 \mathrm{~cm}$ de altura (2,929 contra 2,583 Mcal/kg de MS), o consumo de matéria seca foi levemente inferior na dieta que

Tabela 4 - Consumo médio diário de matéria seca, expresso em kg/animal (CMSD), por $100 \mathrm{~kg}$ de peso vivo (CMSP) e por unidade de peso metabólico (CMSM), de bezerros confinados, de acordo com o tratamento e período de avaliação

Table 4 - Average daily dry matter intake, expressed in $\mathrm{kg}$ per animal (DMID), per $100 \mathrm{~kg}$ of live weight (DMIP), per unit of metabolic weight (DMIM), of confined calves, according to treatment and evaluation period

\begin{tabular}{|c|c|c|c|}
\hline \multirow[t]{2}{*}{$\begin{array}{l}\text { Tratamento } \\
\text { Treatment }\end{array}$} & \multicolumn{2}{|c|}{$\begin{array}{l}\text { Períodos de avaliação } \\
\text { Evaluation periods }\end{array}$} & \multirow[t]{2}{*}{$\begin{array}{l}\text { Média } \\
\text { Mean }\end{array}$} \\
\hline & $\begin{array}{l}12 / 06 \text { a } 13 / 08 \\
06 / 12 \text { to } 08 / 13\end{array}$ & $\begin{array}{l}14 / 08 \text { a } 16 / 10 \\
\text { 08/14 to } 10 / 16\end{array}$ & \\
\hline
\end{tabular}

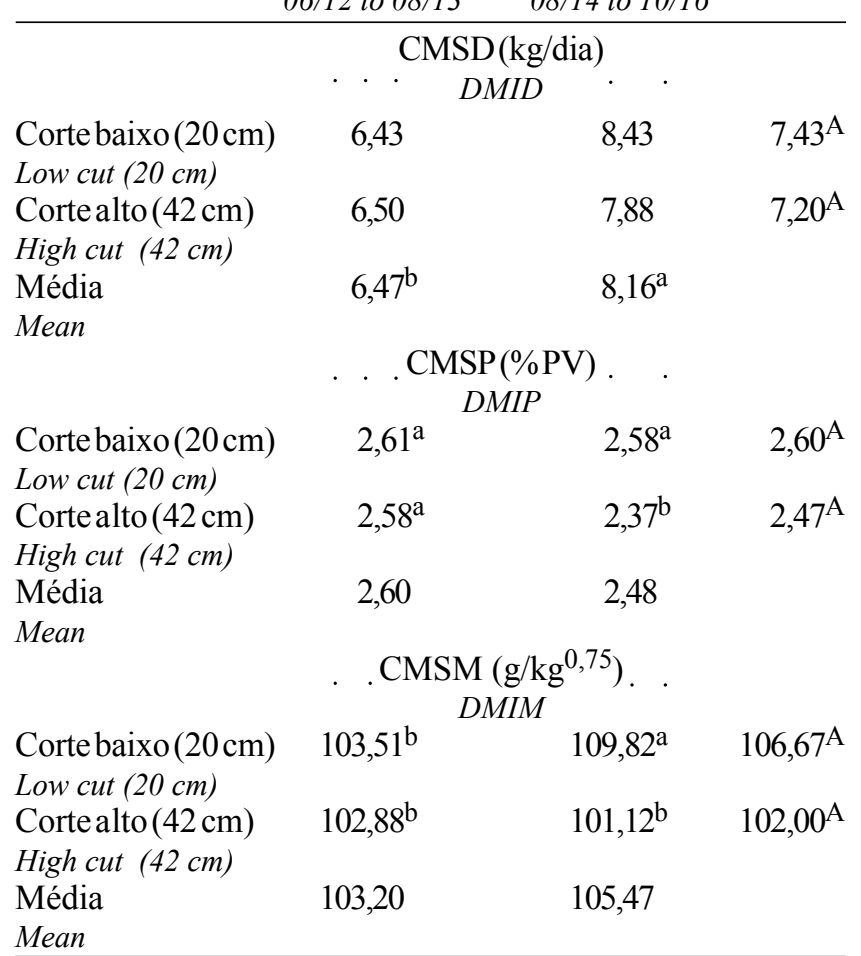

A,B Médias, na coluna, seguidas de letras maiúsculas diferentes para cada variável, diferem $(P<0,05)$ pelo teste $F$.

a,b Médias, com letras minúsculas diferentes, para cada variável, diferem $(P<0,05)$ pelo teste Tukey.

$A, B$ Means, within a column, followed by different capital letters, are different $(P<.05)$ by $F$ test.

a,b Means, followed by different small letters, are different $(P<.05)$ by Tukey test. 
incluía a silagem proveniente de plantas submetidas a corte alto (Tabela 4), resultando em consumo de energia similar.

$\mathrm{Na}$ análise dos períodos de confinamento, o CEDD foi superior $(\mathrm{P}<0,05)$ para o segundo período comparativamente ao primeiro período $(19,66$ contra 25,35 $\mathrm{Mcal} / \mathrm{dia}$ ), apresentando incremento de $28,9 \%$. Este aumento se deve ao crescente CMSD dos bezerros, em função do aumento do peso dos animais, associado à redução da relação volumoso:concentrado de 60:40 para 50:50, que causou o aumento da concentração energética das dietas.

Os CED, expressos por porcentagem do peso vivo (CEDP) e por unidade de tamanho metabólico (CEDM), apresentaram interação significativa entre altura de corte da planta do milho e período de avaliação (Tabela 5). A dieta alimentar que incluiu silagem de milho colhida a $42 \mathrm{~cm}$ proporcionou maior $\operatorname{CEDP}(8,12 \% \mathrm{PV})$ no primeiro período de avaliação frente ao segundo período $(7,57 \% \mathrm{PV})$, o que representou diminuição na ordem de $6,8 \%$. Situação inversa foi observada entre os períodos do confinamento, ao se analisarem as médias do CMSP dos animais cuja dieta tiveram incluída silagem de milho colhida a $20 \mathrm{~cm}$, quando a relação volumoso:concentrado foi reduzida de 60:40 para 50:50, verificando-se maior consumo $(\mathrm{P}<0,05)$ no segundo período $(7,82 \% \mathrm{PV})$ em relação ao primeiro período $(7,66 \% \mathrm{PV})$.

Nos animais cuja dieta incluiu silagem proveniente de plantas submetidas a corte baixo $(20 \mathrm{~cm})$, observaram-se maiores CEDM no segundo período de confinamento $\left(0,332 \mathrm{~g} / \mathrm{kg}^{0,75}\right)$ frente ao primeiro período $\left(0,304 \mathrm{~g} / \mathrm{kg}^{0,75}\right)$, demonstrando que o incremento energético das dietas experimentais, definido pelo aumento na ordem de $10 \%$ na participação da fração concentrada das dietas, promoveu diferença de $9,21 \%$ a favor dos animais alimentados com silagem de corte baixo. Já o CEDM foi similar $(\mathrm{P}>0,05)$ entre os períodos de avaliação do confinamento $\left(0,323 \mathrm{~g} / \mathrm{kg}^{0,75}\right)$ para os animais que tiveram incluído à dieta alimentar a silagem de milho colhida $\mathrm{a} 42 \mathrm{~cm}$.

Houve interação significativa entre altura de corte e período de avaliação do confinamento para as variáveis ganho de peso médio diário (GMD), conversão alimentar (CA) e eficiência energética (CE). Observa-se na Tabela 6 que o GMD dos animais que receberam a silagem de corte baixo aumentou $(\mathrm{P}<0,05)$ do primeiro para o segundo período. Já nos animais que receberam a silagem de corte alto houve leve redução não-significativa no GMD. O aumento de
$11,50 \%$ no GMD do primeiro para o segundo período nos animais alimentados com a silagem de corte baixo deve-se ao incremento do consumo de energia expresso em CEDD (35,14\%), CEDP (2,1\%) e CEDM $(9,21 \%)$. Já nos animais que receberam a silagem de corte alto, o leve decréscimo no GMD do primeiro para o segundo período foi em função do menor incremento do consumo de energia expresso em CEDD (23,22\%), da queda no CEDP (6,77\%) e da manutenção do CED, quando expresso em CEDM.

Tabela 5 - Consumo médio diário de energia digestível, expresso por Mcal/animal (CEDD), por $100 \mathrm{~kg}$ de peso vivo (CEDP) e por unidade de peso metabólico (CEDM), de bezerros confinados, de acordo com o tratamento e período de avaliação

Table 5 - Average daily digestible energy intake, expressed in Mcal per animal (DEID), per $100 \mathrm{~kg}$ of live weight (DEIP) , per unit of metabolic weight (DEIM), of confined calves, according to the treatment and evaluation period

\begin{tabular}{llll}
\hline $\begin{array}{l}\text { Tratamento } \\
\text { Treatment }\end{array}$ & \multicolumn{2}{c}{$\begin{array}{c}\text { Períodos de avaliação } \\
\text { Evaluation periods }\end{array}$} & $\begin{array}{c}\text { Média } \\
\text { Mean }\end{array}$ \\
\cline { 2 - 3 } & $12 / 06$ a $13 / 08$ & $14 / 08$ a $16 / 10$ & \\
& $06 / 12$ to $08 / 13$ & $08 / 14$ to $10 / 16$ & \\
\hline
\end{tabular}

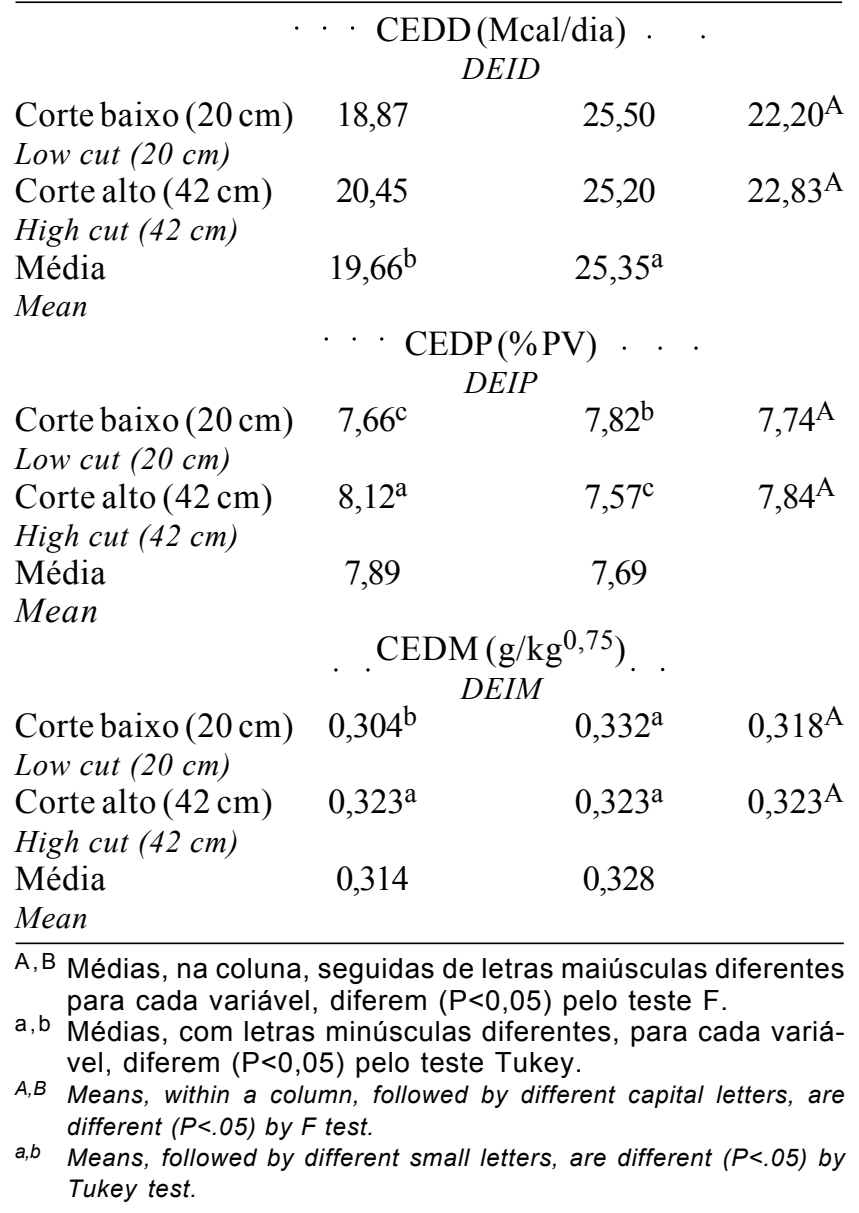


Restle et al. (1999), avaliando a produção de bezerros Braford para abate aos 12 meses, alimentados com silagem de milho colhida às alturas de 16 e $46 \mathrm{~cm}$, não observaram diferença estatística referente aos parâmetros ganho de peso médio diário $(1,062$ contra $1,080 \mathrm{~kg} / \mathrm{dia})$ e conversão alimentar $(6,42$ contra $6,30 \mathrm{~kg}$ de $\mathrm{MS} / \mathrm{kg}$ de ganho de peso). Resultados semelhantes ao presente trabalho foram observados por Rosa et al. (2001), avaliando o efeito da silagem de diferentes híbridos de milho sobre o desempenho

Tabela 6 - Ganho de peso médio diário (GMD), conversão alimentar (CA) e eficiência energética (CE) de bezerros terminados em confinamento, de acordo com a fonte de volumoso e período de avaliação

Table 6 - Means for average daily weight gain (ADG), feed conversion (FC) and energy efficiency (EE) for feedlot finished calves, according to the roughage source and evaluation period

\begin{tabular}{|c|c|c|c|}
\hline \multirow[t]{2}{*}{$\begin{array}{l}\text { Tratamento } \\
\text { Treatment }\end{array}$} & \multicolumn{2}{|c|}{$\begin{array}{l}\text { Períodos de avaliação } \\
\text { Evaluation periods }\end{array}$} & \multirow[t]{2}{*}{$\begin{array}{l}\text { Média } \\
\text { Mean }\end{array}$} \\
\hline & $\begin{array}{l}12 / 06 \text { a } 13 / 08 \\
06 / 12 \text { to } 08 / 13\end{array}$ & $\begin{array}{l}14 / 08 \text { a } 16 / 10 \\
08 / 14 \text { to } 10 / 16\end{array}$ & \\
\hline \multirow{5}{*}{$\begin{array}{l}\text { Corte baixo }(20 \mathrm{~cm}) \\
\text { Low cut }(20 \mathrm{~cm}) \\
\text { Corte alto }(42 \mathrm{~cm}) \\
\text { High cut }(42 \mathrm{~cm}) \\
\text { Média } \\
\text { Mean }\end{array}$} & \multicolumn{2}{|c|}{$\begin{array}{c}\mathrm{GMD}(\mathrm{kg} / \mathrm{dia}) \cdot \\
A D G\end{array}$} & \\
\hline & 1) $1,198^{b}$ & $1,336^{\mathrm{a}}$ & $1,267^{\mathrm{A}}$ \\
\hline & $1,352^{\mathrm{a}}$ & $1,228^{\mathrm{ab}}$ & $1,290^{\mathrm{A}}$ \\
\hline & 1,275 & 1,282 & \\
\hline & \multicolumn{2}{|c|}{$\begin{array}{c}\mathrm{CA}(\mathrm{CMSD} / \mathrm{GMD}) \\
F C(D M I D / A D G)\end{array}$} & \\
\hline \multirow{4}{*}{$\begin{array}{l}\text { Corte baixo }(20 \mathrm{~cm}) \\
\text { Low cut }(20 \mathrm{~cm}) \\
\text { Corte alto }(42 \mathrm{~cm}) \\
\text { High cut }(42 \mathrm{~cm}) \\
\text { Média } \\
\text { Mean }\end{array}$} & $5,39^{\mathrm{b}}$ & $6,34^{\mathrm{a}}$ & $5,87^{\mathrm{A}}$ \\
\hline & $4,82^{\mathrm{C}}$ & $6,43^{\mathrm{a}}$ & $5,62^{\mathrm{A}}$ \\
\hline & 5,10 & 6,39 & \\
\hline & $\begin{array}{l}\mathrm{CE}(\mathrm{C} \\
E E(1\end{array}$ & $\begin{array}{l}\mathrm{D} / \mathrm{GMD}) \\
D / A D G)\end{array}$ & \\
\hline $\begin{array}{l}\text { Corte baixo }(20 \mathrm{~cm}) \\
\text { Low cut }(20 \mathrm{~cm})\end{array}$ & $15,81^{b}$ & $19,18^{\mathrm{a}}$ & $17,50^{\mathrm{A}}$ \\
\hline $\begin{array}{l}\text { Corte alto }(42 \mathrm{~cm}) \\
\text { High cut }(42 \mathrm{~cm})\end{array}$ & $15,14^{\mathrm{b}}$ & $20,56^{\mathrm{a}}$ & $17,85^{\mathrm{A}}$ \\
\hline $\begin{array}{l}\text { Média } \\
\text { Mean }\end{array}$ & 15,47 & 19,87 & \\
\hline
\end{tabular}

A,B Médias, na coluna, seguidas de letras maiúsculas diferentes para cada variável, diferem $(P<0,05)$ pelo teste $F$.

$a, b$ Médias, com letras minúsculas diferentes, para cada variável, diferem $(P<0,05)$ pelo teste Tukey.

$A, B$ Means, within a column, followed by different capital letters, are different $(P<.05)$ by $F$ test.

$a, b$ Means, followed different small letters, for each variable, are different $(P<.05)$ by Tukey test. de bezerros confinados, com valores médios para o GMD de $1,283 \mathrm{~kg} / \mathrm{dia}$ e para a CA de 5,09 $\mathrm{kg}$ de $\mathrm{MS} / \mathrm{kg}$ de ganho de peso, quando a fonte de volumoso testada foi a silagem de milho do híbrido AG-5011.

Na primeira fase do confinamento dos animais, observou-se melhor $(\mathrm{P}<0,05)$ resposta animal com relação à transformação da matéria seca consumida em ganho de peso $(4,82$ contra 5,39$)$ para os animais cuja dieta incluiu silagem de milho colhida a $42 \mathrm{~cm}$. A melhor conversão alimentar dos animais alimentados com a silagem de corte alto no primeiro período foi, em parte, devido ao seu bom desempenho em termos de GMD (1,352 contra 1,198 kg), o que representou diferença de $12,85 \%$ sobre o GMD dos animais alimentados com a silagem de corte baixo.

Na segunda fase do confinamento, não se observou diferença significativa na conversão alimentar entre os animais alimentados com a silagem de corte alto $(6,43)$ e os alimentados com a silagem de corte baixo $(6,34)$. No tratamento com silagem de corte baixo, os animais necessitaram, no segundo período, de 17,63\% mais matéria seca por $\mathrm{kg}$ de ganho de peso que no primeiro período, já nos animais do tratamento com silagem de corte alto o aumento foi de $33,40 \%$. A queda na eficiência alimentar no segundo período já era esperada, em função do aumento de peso dos animais, que resultou em maiores exigências de mantença, e da composição do ganho, já que os animais vão acumulando mais gordura, à medida que a terminação avança. Verifica-se que o aumento da energia da dieta, causado pelo incremento da fração concentrado, não impediu a queda na eficiência alimentar.

A eficiência de transformação da ED consumida em ganho de peso dos animais alimentados com silagem de corte baixo e corte alto não diferiu $(\mathrm{P}>0,05)$ tanto na primeira fase do confinamento (15,81 contra 15,14 $\mathrm{Mcal} / \mathrm{kg}$ de PV) como na segunda fase (19,18 contra $20,56 \mathrm{Mcal} / \mathrm{kg}$ de ganho de peso), respectivamente.

Observa-se, na Tabela 7 , que o peso final, o rendimento de carcaça e o peso de carcaça fria foram similares $(\mathrm{P}>0,05)$ para os animais alimentados com as duas silagens. Verifica-se que a gordura de cobertura, embora sem diferença significativa $(\mathrm{P}=0,1322)$, foi numericamente superior nos animais que tiveram maior concentração energética na dieta. Restle et al. (2000) também verificaram que a utilização da silagem de milho obtida com o corte alto $(46 \mathrm{~cm})$, para produção do novilho superprecoce, resultou em maior porcentagem de gordura na carcaça. Em ambas as dietas, os animais apresentaram peso de

R. Bras. Zootec., v.31, n.3, p.1235-1244, 2002 
carcaça fria acima dos $180 \mathrm{~kg}$, bem como gordura de cobertura adequada (de 3 a $6 \mathrm{~mm}$ ), exigidos pelos frigoríficos em animais superprecoces no Sul do país, visando o consumo interno.

Considerando o período total do confinamento, verifica-se que o desempenho dos animais alimentados com ambas as silagens foi similar. Portanto, para o híbrido AG-5011, não se recomenda a elevação da altura de corte das plantas para $42 \mathrm{~cm}$, pois representa redução na massa verde ensilada de $9,5 \%$ por hectare.

Tabela 7 - Peso inicial, de fazenda e de carcaça fria, rendimento de carcaça e espessura de gordura de bezerros terminados em confinamento, de acordo com a fonte de volumoso

Table 7 - Means for initial, slaughter and cold carcass weight, dressing percentage and subcutaneous fat thickness for feedlot finished calves, according to roughage source

\begin{tabular}{|c|c|c|c|c|c|}
\hline $\begin{array}{l}\text { Tratamento } \\
\text { Treatment }\end{array}$ & $\begin{array}{c}\text { Peso } \\
\text { inicial }(\mathrm{kg}) \\
\text { Initial } \\
\text { weight }(\mathrm{kg})\end{array}$ & $\begin{array}{c}\text { Peso de } \\
\text { abate (kg) } \\
\text { Slaughter } \\
\text { weight (kg) }\end{array}$ & $\begin{array}{c}\text { Peso de carcaça } \\
\text { fria }(\mathrm{kg}) \\
\text { Cold carcass } \\
\text { weight }(\mathrm{kg})\end{array}$ & $\begin{array}{c}\text { Rendimento de } \\
\text { carcaça }(\%) \\
\text { Dressing } \\
\text { percentage }(\%)\end{array}$ & $\begin{array}{c}\text { Espessura de } \\
\text { gordura (mm) } \\
\text { Subcutaneous } \\
\text { fat thickness (mm) }\end{array}$ \\
\hline $\begin{array}{l}\text { Corte baixo }(20 \mathrm{~cm}) \\
\text { Low cut }(20 \mathrm{~cm})\end{array}$ & $208,5^{\mathrm{A}}$ & $368,2 \mathrm{~A}$ & $195,7^{\mathrm{A}}$ & $53,08^{A}$ & $3,67^{\mathrm{A}}$ \\
\hline $\begin{array}{l}\text { Corte alto }(42 \mathrm{~cm}) \\
\text { High cut }(42 \mathrm{~cm})\end{array}$ & $209,3^{\mathrm{A}}$ & $371,8 \mathrm{~A}$ & $195,3^{\mathrm{A}}$ & $52,46^{\mathrm{A}}$ & $5,67^{\mathrm{A}}$ \\
\hline
\end{tabular}

Médias, na coluna, para cada variável, seguidas de letras iguais não diferem $(P>0,05)$ pelo teste $F$.

Means, within a column, for each variable, followed by the same letters, do not differ $(P>.05)$ by $F$ test.

\section{Conclusões}

Embora o sistema de manipulação da altura de colheita das plantas de milho a $42 \mathrm{~cm}$ tenha melhorado o valor nutritivo da silagem de milho, os parâmetros relativos ao consumo de alimentos, ao ganho de peso médio diário e à conversão alimentar não foram afetados.

\section{Literatura Citada}

AGRICULTURAL RESEARCH COUNCIL - ARC. The nutrients requirements of ruminants livestock. Technical review by Agricultural Research Council working Party, London, 1980. 351p.

ALLEN, M.S. Physical constrains on voluntary in take of forages by ruminants. Journal of Animal Science, v.74, p.30633075, 1996.

ALVES FILHO, D.C.; RESTLE, J.; BRONDANI, I.L. et al. Silagem de sorgo ou milho para terminação de novilhos em confinamento. In: REUNIÃO ANUAL DA SOCIEDADE BRASILEIRA DE ZOOTECNIA, 37., 2000, Viçosa. Anais... São Paulo: SBZ/Gmosis, [2000] 17par. CD-ROM. Nutrição de ruminantes. NUR-141

ASSOCIATION OF OFFICIAL ANALYTICAL CHEMISTS AOAC. Official methods of analysis. 14.ed. Washington, D.C.: 1984. 1141p.

BRASIL. Ministério da Agricultura. Levantamento de reconhecimento de solos do Rio Grande do Sul. Rio de Janeiro:
Departamento Regional de Pesquisa Agropecuária: Divisão de Pesquisas Pedológicas, 1973. 431p. (DNPEA, Boletim Técnico, 30).

BRONDANI, I.L.; ALVES FILHO, D.C.; BERNARDES, R.A.C. Silagem de alta qualidade para bovinos. In: RESTLE, J. (Ed.) Eficiência na produção de bovinos de corte. Santa Maria: Universidade Federal de Santa Maria, 2000. p.185-204.

BRONDANI, I.L.; SAMPAIO, A.A.M.; RESTLE, J. et al. Desempenho de tourinhos jovens de diferentes grupos genéticos confinados e alimentados com dois níveis de energia. In: REUNIÃO ANUAL DA SOCIEDADE BRASILEIRA DE ZOOTECNIA, 38., 2001, Piracicaba. Anais... Piracicaba: Sociedade Brasileira de Zootecnia, 2001. p.1185-1186.

FORBES, J.M. Integration of regulatory signals controlling forage intake in ruminants. Journal of Animal Science, v.74, p.3029-3035, 1996.

GOERING, H.K.; Van SOEST, P.J. Forage fiber analysis: apparatus reagents, procedures and some applications. Washington, D.C.: 1970. (Agricultural Handbook, 379)

ILLIUS, A.W.; JESSOP, N.S. Metabolic constrains on voluntary intake in ruminants. Journal of Animal Science, v.74, p.3052-3062, 1996.

McDonald, P.; Henderson, N.; Heron, S. The biochemistry of silage. 2.ed. Marlow: Chalcombe publications, 1991. 339p.

MERTENS, D.R. Regulation of forage intake. In: FAHEY Jr., G.C.; MOSER, L.E.; MERTENS, D.R. (Eds.). Forage quality, evaluation and utilization. Madison: American Society of Agronomy, Crop Science of America, Soil Science of America, 1994. p.450-493.

R. Bras. Zootec., v.31, n.3, p.1235-1244, 2002 
MOREnO, J.A. Clima do Rio Grande do Sul. Porto Alegre: Secretaria da Agricultura. 1961.41p.

NATIONAL RESEARCH COUNCIL - NRC. Nutrient requirements of domestic animals. 6.ed.rev. Washington, D.C.: National Academy Press, 1984. 90p.

NUSSIO, L.G. Produção de silagem de alta qualidade. In: REUNIÃO NACIONAL DO MILHO E SORGO, 19., 1992, Porto Alegre. Anais... Porto Alegre: Secretaria da Agricultura e do Abastecimento, 1992. p.155-175.

PIMENTEL, J.J.O.; SILVA, J.F.C.; VALADARES FILHO, S.C. et al. Efeito da Suplementação protéica no valor nutritivo de silagens de milho e sorgo. Revista Brasileira de Zootecnia, v.27, n.5, p.1042-1049, 1998

RESTLE, J.; EIFERT, E.C.; BRONDANI, I. et al. Produção de terneiros para abate aos 12 meses, alimentados com silagens de milho colhido a duas alturas de corte, associadas a dois níveis de concentrado. In: REUNIÃO ANUAL DA SOCIEDADE BRASILEIRA DE ZOOTECNIA, 36., 1999, Porto Alegre. Anais... São Paulo: Sociedade Brasileira de Zootecnia /Gmosis, [1999] 17par. CD-ROM. Nutrição de ruminantes. NUR-143.

RESTLE, J.; EIFERT, E.C.; BRONDANI, I.L. et al. Avaliação da altura de corte da silagem e dos níveis de concentrado na produção de terneiros para abate aos 12 meses de idade. 2 Características da carcaça. In: REUNIÃO ANUAL DA SOCIEDADE BRASILEIRA DE ZOOTECNIA, 37., 2000, Viçosa. Anais... São Paulo: Sociedade Brasileira de Zootecnia/Gmosis, [2000] 17par. CD-ROM. Nutrição de ruminantes. NUR-527
ROSA, J.R.P.; SILVA, J.H.S.; RESTLE, J. et al. Avaliação de diferentes híbridos de milho (Zea mays L.) para produção de silagem. 3. Desempenho de novilhos em confinamento. In: REUNIÃO ANUAL DA SOCIEDADE BRASILEIRA DE ZOOTECNIA, 38., 2001, Piracicaba. Anais... Piracicaba: Sociedade Brasileira de Zootecnia, 2001. p.1380-1381.

SAS INSTITUTE. SAS/STAT user's guide: statistics. 4.ed. Version 6. v.2. Cary: 1993. 943p.

TILLEY, J.M.; TERRY, R.A. A two-stage technique for the in vitro digestion of forage crops. Journal British Grassland Society, v.18, p.104-111, 1963.

Recebido em: 15/10/01

Aceito em: 08/02/02 